\title{
ANALISIS PENGARUH KUALITAS PELAYANAN DAN KUALITAS PRODUK TERHADAP KEPUASAN NASABAH DI PT BANK DANAMON INDONESIA CABANG BINTARO TANGERANG SELATAN
}

\author{
Endah Dwi Rosanti \\ UniSadhuGuna Business School \\ Ocimoci75@gmail.com
}

\section{Abstract}

This study aims to examine and analyze the effect of service quality and product quality on customer satisfaction in PT Bank Danamon Bintaro Branch South Tangerang. Data was collected through questionnaires distributed and implemented on 100 (one hundred) customers at PT Bank Danamon Bintaro Branch. Data analysis in this study using SPSS version 20. Penenlitian is done sampling by non probability sampling and using accidental sampling method. While the data testing techniques used in this study include the validity test with factor analysis, reliability test with Alpha Cronbach. Test the classical assumption and multiple linear regression analysis, to test and prove the research hypothesis.

The results of the analysis show that service quality has an effect on customer satisfaction and product quality also has an effect on customer satisfaction. Based on the results of tests conducted with partial test ( $t$ test) there is a positive correlation of service quality variable to customer satisfaction. Similarly, simultaneous test ( $F$ test) shows that overall variable of service quality influence $(X 1)$ and product quality (X2) have significant influence to customer satisfaction. $R$ Square value of 0.664, means that the quality of service and product quality

are together able to explain customer satisfaction variable of $66.4 \%$ while the rest of $33.6 \%$ are other factors not examined in this study.

Keywords: service quality, product quality, and customer satisfaction

\section{Pendahuluan}

Bank adalah salah satu lembaga keuangan yang bergerak pada bidang keuangan. Menurut Undang-undang Negara Republik Indonesia Nomor 10 Tahun 1998 Tanggal 10 November 1998 tentang perbankan, yang dimaksud bank adalah badan usaha yang menghimpun dana dari masyarakat dalam bentuk simpanan dan menyalurkannya kepada masyarakat dalam bentuk kredit dan atau bentuk-bentuk lainnya dalam rangka meningkatkan taraf hidup rakyat banyak. Dari pengertian bank menurut Undang-undang Negara Republik Indonesia Nomor 10 Tahun 1998 dapat disimpulkan bahwa usaha perbankan meliputi tiga kegiatan, yaitu menghimpun dana, menyalurkan dana, dan memberikan jasa bank lainnya. Kegiatan menghimpun dan menyalurkan dana merupakan kegiatan utama bank, sedangkan memberikan jasa bank lainnya hanya kegiatan pendukung saja. Adapun bank mengumpulkan dana dari masyarakat dalam bentuk simpanan tabungan, giro, dan deposito.

Memasuki era globalisasi semakin banyak bank-bank yang hadir dan menawarkan berbagai macam keuntungan untuk nasabah. Persaingan pun semakin ketat. Tidak hanya 
memberikan keuntungan untuk nasabah saja, namun bank juga harus mempunyai kewajiban untuk memerhatikan kepuasan dari nasabah. Kepuasan nasabah merupakan hal yang paling penting dalam keberlangsungan hidup sebuah bank sehingga akan terciptanya rasa kepercayaan yang tinggi dari nasabah. Berawal dari rasa kepercayaan yang tinggi maka akan terbentuk loyalitas nasabah terhadap bank tersebut. Seiring berjalannya waktu, nasabah semakin cerdas dan cermat dalam memilih bank untuk dapat mengelola keuangan merupakan isyarat bahwa Bank Danamon Bintaro harus lebih berinovasi dan memerhatikan kepuasan nasabah. Karena sebagai pengguna jasa kini nasabah semakin selektif dalam memilih bank untuk menitipkan dana yang dimiliki guna menghindari risiko kehilangan dana akibat buruknya kinerja suatu bank. Kepuasan nasabah ditentukan oleh kualitas pelayanan dan kualitas produk, sehingga Bank Danamon Bintaro wajib untuk menjadikan kualitas sebagai hal yang utama. Jika ada ketidakpuasan nasabah seperti keluhan atau hak-hak nasabah tidak terpenuhi, maka hal tersebut bisa menjadi bumerang bagi Bank Danamon Bintaro itu sendiri. Contoh dari keluhan dan hak-hak nasabah tidak boleh diabaikan seperti misalnya pelayanan yang lambat dan tidak ramah, promosi produk tabungan yang kurang menguntungkan, biaya administrasi yang terlalu besar, kurangnya informasi yang diberikan kepada nasabah sehingga timbul kekecewaan dengan produk yang digunakan atau ketidakpahaman nasabah terhadap produk tabungan yang digunakan, kurangnya jumlah fasilitas yang diberikan oleh bank, seperti misalnya jumlah mesin ATM yang tidak banyak. Jika ada perbedaan antara harapan dan kenyataan yang diperoleh, maka bank harus mengantisipasinya. Bank Danamon Bintaro III harus berusaha semaksimal mungkin agar mendapat tempat di hati nasabah, baik nasabah lama maupun nasabah baru.

\section{Metode Penelitian}

Metode yang digunakan dalam penelitian ini adalah metode deskriptif kuantitatif, Metode kuantitatif adalah ilmu dan seni yang berkaitan dengan tata cara (metode) pengumpulan data, analisis data, dan interprestasi hasil analisis untuk mendapatkan informasi dan pengambilan keputusan. Penelitian ini akan melakukan survey dengan menggunakan alat kuesioner sebagai instrumen pengumpulan data dan hasil dari kuesioner tersebut akan diolah dengan software SPSS versi 20.

\section{A.Populasi dan Sampel}

Dalam penelitian ini pengambilan sampel dilakukan secara non probability sampling dengan menggunakan metode accidental sampling atau disebut juga metode convenivence sampling. Accidental sampling adalah suatu metode pengambilan sampel dimana sampel yang diambil dari siapa saja yang kebetulan ditemui atau siapapun yang dipandang oleh peneliti cocok sebagai sumber data (Murti Sumarni dan Wahyuni, 2006). Jadi pengambilan sampel dalam penelitian ini tergantung dari adanya pengunjung yang datang dan dilakukan dengan menanyai siapa saja pengunjung yang membeli produk PT Bank Danamon Bintaro. 


\section{B. Teknik Pengumpulan Data}

Pengumpulan data merupakan salah satu kegiatan yang dilakukan dalam proses penelitian. Dalam suatu penelitian ilmiah metode pengumpulan data dimaksudkan untuk memperoleh bahan-bahan yang relevan, akurat, dan terpercaya Supranto (dalam Haryobudi, 2010). Adapun teknik pengumpulan data sebagai berikut:

\section{1) Pengumpulan Data Primer}

a) Data Primer

Data primer yaitu data yang diperoleh dari hasil penelitian langsung secara empirik kepada pelaku langsung atau yang terlibat langsung dengan menggunakan teknik pengumpulan data tertentu. Data primer adalah data yang didapat dari sumber pertama, baik individu atau perseorangan seperti hasil wawancara atau hasil pengisian kuesioner yang biasa dilakukan oleh peneliti. Sumber data yang digunakan dalam penelitian yang dilakukan oleh penulis adalah sumber data primer.

b) Data Sekunder

Data sekunder yaitu data yang diperoleh dari pihak lain atau hasil penelitian pihak lain.

\section{2) Pengumpulan data Sekunder}

Metode pengumpulan data sekunder yaitu dengan metode dokumentasi. Metode dokumentasi dilakukan peneliti dengan cara: mengamati dengan membaca, melakukan kajian teoritik, dan mencatat. Dilakukan sebagai langkah relevan dalam studi pustaka teori serta studi pustaka hasil penemuan.

\section{Tabel 1 Definisi Variabel Operasional}

\begin{tabular}{|c|c|c|}
\hline Variabel & Konsep Variabel & Indikator \\
\hline $\begin{array}{l}\text { Kualitas Pelayanan } \\
\text { (X1) }\end{array}$ & $\begin{array}{l}\text { a. Reliability } \\
\text { b. Responsiveness }\end{array}$ & $\begin{array}{l}\text { a. Tepat waktu dalam melaksanakan keperluan } \\
\text { nasabah }\end{array}$ \\
\hline Sumber: & $\begin{array}{l}\text { c. Assurance } \\
\text { d. Empathy }\end{array}$ & $\begin{array}{l}\text { b. Bersedia dalam menanggapi semua keluhan } \\
\text { nasabah }\end{array}$ \\
\hline \multirow{2}{*}{$\begin{array}{l}\text { Fandy Tjiptono } \\
(2012: 174)\end{array}$} & e. Tangibles & $\begin{array}{l}\text { c. Pegawai Bank memiliki pengetahuan yang } \\
\text { cukup }\end{array}$ \\
\hline & & $\begin{array}{l}\text { d. Memperhatikan kepentingan nasabah } \\
\text { e. Teknologi yang maju untuk memudahkan } \\
\text { nasabah bertransaksi }\end{array}$ \\
\hline \multirow[t]{2}{*}{ Kualitas Produk (X2) } & a. Performance & a. Produk sesuai dengan kebutuhan nasabah. \\
\hline & b. Durability & b. Produk tabungan yang dikeluarkan oleh bank \\
\hline Sumber: & $\begin{array}{l}\text { c. Feature } \\
\text { d. Realibility }\end{array}$ & $\begin{array}{l}\text { bersifat tahan lama (bertahan dalam jangka waktu } \\
\text { yang lama). }\end{array}$ \\
\hline \multirow[t]{6}{*}{ Handi Irawan (2002:37) } & e. Conformance & c. Fitur produk sangat menarik, praktis, dan \\
\hline & f. Design & $\begin{array}{l}\text { mempermudah nasabah untuk melakukan } \\
\text { transaksi. }\end{array}$ \\
\hline & & d.Teknologi yang canggih dan terdepan membuat \\
\hline & & produk bank berfungsi sebagaimana mestinya. \\
\hline & & dengan standar yang telah ditentukan. \\
\hline & & $\begin{array}{l}\text { f. Produk memiliki ciri yang unik sehingga dapat } \\
\text { menarik minat nasabah. }\end{array}$ \\
\hline
\end{tabular}




\begin{tabular}{lll}
\hline Kepuasan Nasabah (Y) & a. Positive & a. Kepuasan yang diterima nasabah melebihi \\
Sumber: & Disconfirmation & harapan \\
Engel Blackwell - & b. Simple & b. Kepuasan yang diterima nasabah sesuai dengan \\
Miniar (1990) & Confirmation & harapan. \\
Kotler (2000) & c.Negative & c. Nasabah merasa tidak puas (kepuasan yang \\
& Disconfirmation & diterima nasabah tidak sesuai harapan). \\
\hline
\end{tabular}

\section{Hasil dan Pembahasan}

\section{A. Uji Validitas}

Tabel 2 Uji Validitas Variabel Kualitas Pelayanan (X1)

\begin{tabular}{clll}
\hline \multirow{2}{*}{ Pernyataan } & \multicolumn{3}{c}{ Kualitas Pelayanan (X1) } \\
\cline { 2 - 4 } & Rhitung & rtabel & Keterangan \\
\hline 1 & 0.679 & 0.194 & Valid \\
2 & 0.168 & 0.194 & Valid \\
3 & 0.654 & 0.194 & Valid \\
4 & 0.685 & 0.194 & Valid \\
5 & 0.659 & 0.194 & Valid \\
6 & 0.587 & 0.194 & Valid \\
7 & 0.467 & 0.194 & Valid \\
\hline
\end{tabular}

Sumber: Hasil olahan data SPSS 20

Berdasarkan tabel 2, dapat dilihat bahwa untuk masing-masing pertanyaan pada variabel Kualitas Layanan (X1) seluruh instrument dapat dikatakan valid, karena nilai rhitung yang dihasilkan lebih besar (>) dari pada rtabel yang ada untuk $\mathrm{n}$ $=100$ (seratus) yaitu 0.194 kepemimpinan dinyatakan valid.

\section{Tabel 3 Uji Validitas Kualitas Produk (X2)}

\begin{tabular}{clll}
\hline \multirow{2}{*}{ Pernyataan } & \multicolumn{3}{c}{ Kualitas Produk (X2) } \\
\cline { 2 - 4 } & rhitung & Rtabel & Keterangan \\
\hline 1 & 0.663 & 0.194 & Valid \\
2 & 0.503 & 0.194 & Valid \\
3 & 0.700 & 0.194 & Valid \\
4 & 0.419 & 0.194 & Valid \\
5 & 0.659 & 0.194 & Valid \\
6 & 0.675 & 0.194 & Valid \\
7 & 0.554 & 0.194 & Valid \\
8 & 0.668 & 0.194 & Valid \\
\hline
\end{tabular}

Sumber: Hasil olahan data SPSS 20

Berdasarkan tabel 3, dapat dilihat bahwa untuk masing-masing pertanyaan pada variabel Kualitas Produk (X2) seluruh instrument dapat dikatakan valid, karena nilai $r_{\text {hitung }}$ yang dihasilkan lebih besar $(>)$ dari pada $r_{\text {tabel }}$ yang ada untuk $n=100$ (seratus) yaitu 0.194 


\title{
Tabel 4 Uji Kepuasan Nasabah (Y)
}

\begin{tabular}{clll}
\hline \multirow{2}{*}{ Pernyataan } & \multicolumn{3}{c}{ Kepuasan Nasabah (Y) } \\
\cline { 2 - 4 } & rhitung & rtabel & Keterangan \\
\hline 1 & 0.772 & 0.194 & Valid \\
2 & 0.707 & 0.194 & Valid \\
3 & 0.847 & 0.194 & Valid \\
4 & 0.599 & 0.194 & Valid \\
5 & 0.713 & 0.194 & Valid \\
6 & 0.842 & 0.194 & Valid \\
\hline
\end{tabular}

Sumber : Hasil olahan data SPSS 20

Berdasarkan tabel 4, dapat dilihat bahwa untuk masing-masing pertanyaan pada variabel Kepuasan Nasabah (Y) seluruh instrument dapat dikatakan valid, karena nilai $\mathrm{r}_{\text {hitung }}$ yang dihasilkan lebih besar $(>)$ dari pada $\mathrm{r}_{\text {tabel }}$ yang ada untuk $\mathrm{n}=$ 100 (seratus) yaitu 0.194

\section{B. Uji Realibilitas}

Tabel 5 Hasil Uji Reliabilitas Variabel X1

\author{
Cronbach's

\begin{tabular}{rr} 
Alpha & $\mathrm{N}$ of Items \\
\hline .613 & 7
\end{tabular} \\ Sumber : Hasil Olahan data (SPSS 20)
}

Berdasarkan tabel 5, untuk uji reliabilitas variabel Kualitas Layanan (X1) mempunyai nilai yang sangat tinggi (0.613), sehingga dapat disimpulkan bahwa variabel ini adalah Reliabel.

\section{Uji Reliabilitas Variabel Kualitas Produk (X2)}

\section{Tabel 6 Uji Reliabilitas Variabel Kualitas Produk (X2) Reliability Statistics

\begin{tabular}{rr}
\hline $\begin{array}{c}\text { Cronbach's } \\
\text { Alpha }\end{array}$ & N of Items \\
\hline .746 & 8 \\
\hline
\end{tabular} \\ Sumber: Hasil Olahan Data (SPSS 20)}

Berdasarkan tabel 6, untuk uji reliabilitas variabel Kualitas Produk (X2) mempunyai nilai yang tinggi (0.746), sehingga dapat disimpulkan bahwa variabel ini adalah Reliabel.

\section{Uji Reliabilitas Variabel Kepuasan Nasabah (Y)}

Tabel 7 Uji Realibilitas Variabel Kepuasan Nasabah (Y)

Reliability Statistics

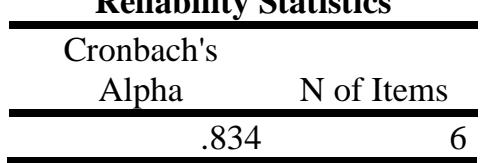

Sumber: Hasil Olahan Data (SPSS 20) 


\section{E. Uji Asumsi Klasik \\ 1. Uji Multikolinearitas}

Tabel 8 Hasil Uji Multikolinearitas

\begin{tabular}{llll}
\hline Model & \multicolumn{3}{c}{ Collinearity Statistics } \\
\cline { 2 - 4 } & Tolerance & VIF \\
\cline { 2 - 4 } (Constant) & & \\
X1 & .504 & 1.983 \\
X2 & .442 & 2.261 \\
\hline
\end{tabular}

Sumber : Hasil Olahan Data (SPSS 20)

Berdasarkan tabel 8, dapat diketahui bahwa nilai Variance Inflation Factor (VIF) dari masing-masing variabel independent tidak memiliki nilai yang lebih dari 10, sehingga dapat disimpulkan bahwa model regresi dalam penelitian ini tidak mengandung multikolinearitas.

\section{F. Uji Heteroskedastisitas}

\section{Hasil Pengujian Heteroskedastitas}

Tabel 9 Hasil Pengujian Heteroskedastisitas

\begin{tabular}{lccccc}
\multicolumn{5}{c}{ Coefficientsa } \\
\hline Model & $\begin{array}{c}\text { Unstandard } \\
\text { ized } \\
\text { Coefficient }\end{array}$ & $\begin{array}{c}\text { Standardi } \\
\text { zed }\end{array}$ & $\mathrm{t}$ & Sig. & $\begin{array}{c}\text { Collin } \\
\text { Coefficie } \\
\text { earity }\end{array}$ \\
& $\mathrm{s}$ & $\mathrm{nts}$ & & & $\begin{array}{c}\text { Statist } \\
\text { ics }\end{array}$ \\
\hline (Consta & -.502 & .977 & & -.514 & .609 \\
$\mathrm{nt})$ & .040 & .048 & .23 & & \\
$\mathrm{X} 1$ & .012 & .036 & 1 & 1.647 & .103 \\
$\mathrm{X} 2$ & & & .05 & .332 & .741 \\
& & & 0 & & \\
\hline
\end{tabular}

a. Dependent Variable: ABRES

Sumber: Hasil olahan data SPSS 20

Berdasarkan hasil pengujian dengan menggunakan metode Glejser, dapat diketahui tidak terjadi gejala Heteroskedastisitas pada model. Hal ini dapat kita lihat dari signifikan X1 $=0.040<$ dari 0.05 , dan X2 signifikan pada $0.012<0.05$.

\section{Hasil Uji Normalitas Data}

One-Sample Kolmogorov-Smirnov

\begin{tabular}{|c|c|}
\hline \multicolumn{2}{|c|}{ Test } \\
\hline & $\begin{array}{c}\text { Standar } \\
\text { dized } \\
\text { Residua } \\
1\end{array}$ \\
\hline $\mathrm{N}$ & 100 \\
\hline Normal Parameters ${ }^{\mathrm{a}, \mathrm{b}}$ & Mean $\quad .000000$ \\
\hline
\end{tabular}




\begin{tabular}{|c|c|c|}
\hline & $\begin{array}{l}\text { Std. } \\
\text { Deviat } \\
\text { ion }\end{array}$ & $\begin{array}{r}.979589 \\
69\end{array}$ \\
\hline \multirow[t]{3}{*}{ Most Extreme Differences } & $\begin{array}{l}\text { Absol } \\
\text { ute }\end{array}$ & .046 \\
\hline & $\begin{array}{l}\text { Positi } \\
\text { ve }\end{array}$ & .027 \\
\hline & $\begin{array}{l}\text { Negati } \\
\text { ve }\end{array}$ & -.046 \\
\hline \multicolumn{2}{|l|}{ Test Statistic } & .046 \\
\hline \multicolumn{2}{|l|}{ Asymp. Sig. (2-tailed) } & $.200^{\mathrm{c}, \mathrm{d}}$ \\
\hline \multicolumn{3}{|l|}{ a. Test distribution is Normal. } \\
\hline \multicolumn{3}{|c|}{ b. Calculated from data. } \\
\hline \multicolumn{3}{|c|}{ c. Lilliefors Significance Correction. } \\
\hline \multicolumn{3}{|c|}{$\begin{array}{l}\text { d. This is a lower bound of the true } \\
\text { significance. }\end{array}$} \\
\hline
\end{tabular}

Berdasarkan tabel di atas, nilai signifikansi (2-tailed) sebesar 0.200, dapat diartikan bahwa nilai signifikansi (2-tailed) alat ukur tersebut berada di atas 0.05 sehingga data dikatakan berdistribusi normal.

\section{Regresi Linear Berganda (Multiple)}

\begin{tabular}{|c|c|c|c|c|c|}
\hline \multirow[b]{2}{*}{ Model } & \multicolumn{3}{|c|}{ Unstandardized Coefficients } & \multirow[b]{2}{*}{$\mathrm{T}$} & \multirow[b]{2}{*}{ Sig. } \\
\hline & & B & Std. Error & & \\
\hline \multirow[t]{3}{*}{1} & $\begin{array}{l}\text { (Const } \\
\text { ant) }\end{array}$ & -2.509 & 1.669 & -1.623 & .108 \\
\hline & $\mathrm{X} 1$ & .239 & .083 & 3.253 & .002 \\
\hline & $\mathrm{X} 2$ & .210 & .061 & 3.932 & .000 \\
\hline
\end{tabular}

Untuk menentukan nilai persamaan regresi linier berganda, yaitu sebagai berikut: $Y^{\prime}=\mathbf{- 2 . 5 0 9}+\mathbf{0 . 2 3 9 X 1}+\mathbf{0 . 2 1 0 X 2}$. Dapat dijelaskan sebagai berikut:

1. Nilai konstanta intersep sebesar -2.509 menyatakan bahwa jika variabel Kualitas Layanan (X1) dan Variabel Produk (X2 tetap (tidak mengalami perubahan) maka nilai variabel Kepuasan Nasabah (Y) akan menurun sebesar 2.509

2. Nilai koefisien regresi variabel Kualitas Layanan (X1) terhadap variabel Kepuasan Pelanggan (Y) adalah sebesar 0.239. Hal ini berarti variabel Kualitas Produk (X1) naik 1 satuan akan meningkatkan Kepuasan Nasabah (Y) sebesar 0.239 dengan asumsi variabel independen dan konstanta dianggap konstan

3. Nilai koefisien regresi variabel Kualitas Produk (X2) terhadap variabel Kepuasan Nasabah (Y) adalah sebesar 0.210. Hal ini berarti variabel Kualitas Produk (X2) naik 1 satuan akan meningkatkan Kepuasan Nasabah (Y) sebesar 0.210 dengan asumsi variabel independen dan konstanta dianggap konstan 


\section{G.Uji Anova (F)}

\begin{tabular}{llrrr}
\hline Model & & df & F & Sig. \\
\hline 1 & Regression & 2 & 49.783 & $.000^{\mathrm{b}}$ \\
& Residual & 97 & & \\
& Total & 99 & & \\
\hline
\end{tabular}

Sumber : Hasil Olahan Data (SPSS 20)

Hasil pengujian secara simultan dengan $\mathrm{N} 2=\mathrm{df} 2=97$ untuk penyebut dan $\mathrm{N} 1=\mathrm{df} 1=2$ untuk pembilang pada taraf nyata yang digunakan adalah 0.05 (5persen). Berdasarkan hasil analisis diperoleh nilai F-hitung sebesar 49,783 dengan signifikansi 0,000. Nilai F-tabel pada tingkat kepercayaan 95 persen (signifikan 0.05) adalah 3.09 (lihat: Tabel F).

Maka dapat disimpulkan bahwa F-hitung > F-tabel $(49,783>3.09)$ dengan signifikansi lebih kecil dari $0.05(0,000<.0 .05)$ yang berarti bahwa variabel Kualitas Pelayanan dan Kualitas Produk berpengaruh signifikan terhadap Kepuasan Nasabah

\section{Kesimpulan}

Sebagai penutup dari penulisan Tugas Akhir ini, berikut ini akan penulis sampaikan kesimpulan dari pembahasan pada bab sebelumnya:

1. Terdapat pengaruh Kualitas Pelayanan dengan Kepuasan Pelanggan, hal tersebut dapat dilihat dari nilai thitung untuk variabel X1 sebesar 3.253, sedangkan nilai ttabel untuk $\mathrm{n}=100$ sebesar 1,984. Jadi 3,253>1,984, dapat disimpulkan bahwa secara parsial variabel Kualitas Pelayanan (X1) berkorelasi Positif terhadap Kepuasan Pelanggan (Y) pada $\alpha=5 \%$.

2. Terdapat pengaruh Kualitas Produk dengan Kepuasan Pelanggan, hal tersebut dapat dilihat nilai t hitung untuk variabel X2 sebesar 3.932, sedangkan nilai t tabel untuk n $=100$ sebesar 1,984. Jadi 3,932>1,984, dapat disimpulkan bahwa secara parsial variabel Kualitas Produk (X2) berkorelasi terhadap Kepuasan Pelanggan (Y) pada $\alpha$ $=5 \%$.

3. Terdapat pengaruh Kualitas Pelayanan dan Kualitas Produk secara bersama-sama atau simultan berkorelasi dengan Kepuasan Pelanggan. Hal tersebut dinilai dari nilai F-hitung sebesar 49,783 dengan signifikansi 0,000. Nilai F-tabel pada tingkat kepercayaan 95 persen (signifikan 0.05) adalah 3.09, dengan F-tabel sebesar 3.09 dengan $n=100$. Maka dapat disimpulkan bahwa F-hitung > F-tabel $(49,783>3.09)$ dengan signifikansi lebih kecil dari $0.05(0,000<.0 .05)$ yang berarti bahwa variabel Kualitas Pelayanan dan Kualitas Produk berpengaruh signifikan terhadap Kepuasan Pelanggan. 


\section{DAFTAR PUSTAKA}

Aritonang. (2005). Kepuasan Pelanggan. Jakarta: Gramedia

Chaniago, Junaidi. (2010). Tabel Distribusi $F$ Untuk Probabilitas 0.05 https://junaidichaniago.files.wordpress.com/2010/04/tabel-f-0-05.pdf

Chaniago, Junaidi. (2010). Tabel Distribusi $t \quad d . f \quad 1 \quad$ sampai 100 http://ledhyane.lecture.ub.ac.id/files/2013/04/tabel-t.pdf

Djaslim Saladin. (2002). Manajemen Pemasaran. Jakarta: Salemba Empat

Goetsch, David L \& Stanley B. Davis. (2000). Kualitas Manajemen. Ahli Bahasa Hendra Teguh dan Ronny A Rusly. Jakarta: Prenhallindo.

Ghozali Imam. (2009). Aplikasi Analisis Multivariate dengan Program SPSS. Universitas Diponogoro, Semarang.

Hamdani, A. (2007). Strategi Pemasaran. Edisi Pertama. Andi Ofset. Yogyakarta.

Handi Irawan. (2002). 10 Prinsip Kepuasan Pelanggan. Jakarta: Elex Media Komputindo.

Husein Umar. (2000). Riset Pemasaran dan Perilaku. Jakarta: Gramedia.

Juwandi, Hendy Irawan. (2004). Kepuasan Pelayanan Jasa. Erlangga. Jakarta.

Kotler, Philip. (2002). Manajemen Pemasaran di Indonesia : Analisis, Perencanaan, Implementasi dan Pengendalian. Salemba Empat. Jakarta.

Lupiyoadi, Rambat. (2001). Manajemen Pemasaran Jasa. Salemba Empat. Jakarta.

Mulyahyo. (2014). Pengertian Produk Defenisi Kualitas, Jakarta. (http://mulyajho.blogspot.co.id/2014/05/pengertian-produk-definisi-kualitas.html).

Murti Sumarti dan Salamah Wahyuni. (2006). Metodologi Penelitian Bisnis, Yogyakarta: Penerbit Andi Yogyakarta.

Nazir, Moh. (2005). Metode Penelitian. Jakarta: Ghalia Indonesia

Rambat Lupiyoadi. (2004). Manajemen Pemasaran Jasa: Teori dan Praktek, Jakarta: Salemba Empat.

Sugiyono. (2010). Statistika untuk Penelitian. Bandung: CV Alfabeta.

Sugiyono. (2012). Metode Penelitian Kuantitatif Kualitatif dan R\&D. Bandung: Alfabeta 
Endah Dwi Rosanti

Suharsimi Arikunto. (2002). Prosedur Penelitian: Suatu Pendekatan Praktek. Jakarta: Rhineka Cipta.

Tjiptono, Fandy. (2001). Strategi Pemasaran. Edisi Pertama. Andi Ofset.Yogyakarta. 